\title{
Audit strategies to reduce hospital admissions for acute asthma
}

\author{
G J Connett, C Warde, E Wooler, W Lenney
}

\begin{abstract}
An eightfold rise in hospital admissions for acute asthma from 1971-85 prompted two studies to audit the admissions policy at the Royal Alexandra Hospital. In the first study the on call senior house officer (SHO) was replaced by an experienced registrar and over a four month period 53 children out of 158 were sent home from the receiving room compared with six out of 39 seen by the SHOs. In the second study an SHO training programme was established together with a home treatment package. Over a 12 month period the on call SHOs assessed 687 children with acute asthma; $229(43.5 \%)$ were deemed fit to be sent home. Only seven of these were readmitted within one week. Diary symptom score cards filled in by parents indicated that children sent home without admission fared no worse at home than those admitted and then discharged for the two weeks after leaving hospital.
\end{abstract}

The development of strategies to improve assessment and immediate management in the hospital receiving room can reduce hospital admissions for acute asthma, allowing more children to be safely managed in the community.

(Arch Dis Child 1993; 69: 202-205)

Royal Alexandra Hospital for Sick Children, Dyke Road, Brighton BN1 3JN

G J Connett

$C$ Warde

E Wooler

W Lenney

Correspondence to: Dr Lenney.

Accepted 6 April 1993

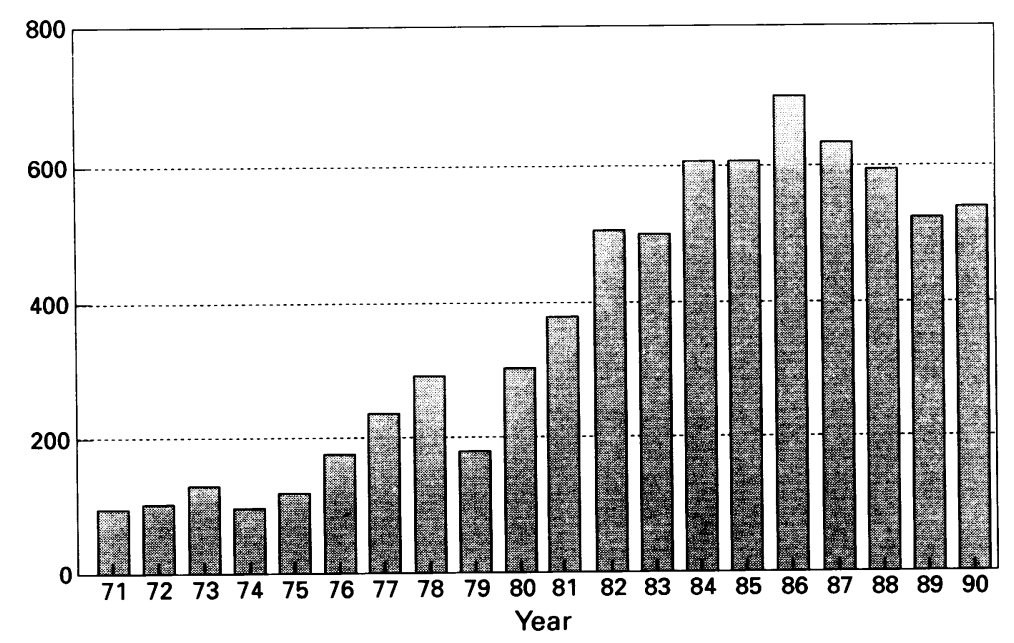

Figure 1 Children with asthma admitted to the Royal Alexandra Hospital.

As health services for children have improved over the last 20 years, there have been substantial changes in the way health care is delivered. In particular there has been a large increase in the number of hospital admissions in children with acute illnesses. ${ }^{1}$ The extent of this increase varies throughout the country. These temporal changes and geographical differences cannot be explained by variations in morbidity alone and are heavily influenced by the extent to which hospital services are organised and provided. ${ }^{2}$ While services have developed to meet local demands for treatment, the resulting patterns of care are not necessarily the most beneficial to children's needs, nor the most cost effective. The largest increase in hospital referrals has been for the treatment of acute asthma, which is the commonest cause of admission. At the Royal Alexandra Hospital in Brighton there was an eightfold rise in admissions from 1971-85. Numbers have since remained relatively constant at between 500 to 600 per year (fig 1). This increase was not due to changes in diagnosis among the children admitted and there were no major changes in the provision of paediatric services from neighbouring hospitals.

The national increase might have been precipitated by the introduction of direct access or 'open door' policies for asthmatic patients. ${ }^{3}$ These were set up to expedite the admission of severe asthmatics, bypassing the general practitioner (GP) and the possible risk of failure to initiate adequate treatment. ${ }^{4}$ At the same time as these measures were introduced, nebulised bronchodilators became widely available in hospitals. ${ }^{5}$ The growing acceptance of self referral and the availability of a preferred form of inpatient treatment are likely factors underlying the increase in asthma admissions.

The following studies were designed to audit our admission policy at the Royal Alexandra Hospital to enable a long term change in the way the hospital is used by asthmatic children.

\section{Patients, methods, and results}

STUDY 1

Like many centres, acute referrals are assessed by the most junior member of the paediatric team and admission often follows without referral to the registrar. The first study aimed to decrease hospital admissions by replacing the senior house officer (SHO) who was on call with an experienced assessor and the facility to offer parents home treatment.

Protocol

Over a four month period (October 1990-January 1991) $80 \%$ of acute asthma referrals over the age of 18 months were assessed by the same registrar (GJC). The remaining $20 \%$ were seen by the SHO who was on call as usual. The registrar was available day and night and patients seen by the SHOs were referrals during specified 24 hour 'time off' periods. After taking a full history, each child 
Table 1 Numbers sent home in study 1 compared with previous years

\begin{tabular}{llcll}
\hline Year & $\begin{array}{l}\text { Total No } \\
\text { presenting }\end{array}$ & $\begin{array}{l}\text { No seen by } \\
\text { registrar }\end{array}$ & $\begin{array}{l}\text { Total } \\
\text { admitted }\end{array}$ & $\begin{array}{l}\text { Total } \\
\text { sent home }\end{array}$ \\
\hline 1988 & 231 & - & 210 & 21 \\
1989 & 241 & - & 220 & 21 \\
1990 & 197 & 158 & 138 & 59 \\
\hline
\end{tabular}

was assessed before and at least 10 minutes after receiving $5 \mathrm{mg}$ of nebulised salbutamol. Assessments included measurements of peak flow and pulse oximetry whenever possible. The decision to admit was based on the response to the nebuliser and the considered ability of the parents to continue treatment at home. Those sent home were given $2 \mathrm{mg} / \mathrm{kg}$ of oral prednisolone and instructed to repeat the dose for two further days if symptoms persisted. If children were not using a suitable bronchodilator, an attempt was made to teach them the use of a metered dose inhaler through a spacer device. All parents were given written information about treatment. This included advice to return if the prednisolone was vomited back or if bronchodilators were needed more often than every four hours.

\section{Results}

Out of 197 children referred, $122(62 \%)$ were self referrals and $45(23 \%)$ presented with their first episode of severe wheeze. One hundred and fifty eight children were assessed by the registrar and 53 of these were sent home, five reattended within one week of which only one was subsequently admitted to hospital. The SHOs on call saw 39 children and six were sent home. One reattended within one week and was admitted. Analysis by $\chi^{2}$ compared children sent home during the study with numbers sent home in similar periods in the two years before the study. This showed a statistically significant difference favouring the study period $(\mathrm{p}<0.001$, table 1$)$.

\section{STUDY 2}

The first study suggests that experienced assessment and the facility to offer effective home treatment could reduce the number of acute asthmatics needing inpatient treatment.

In an ideal world, children with acute asthma would have free access at all times to familiar asthma clinic staff who had time and resources to make adequate assessments and provide continuity of follow up. ${ }^{6}$ This is not easily achievable within the limitations of existing services and is probably not cost effective for most hospitals. The second study attempted to go some way towards meeting these requirements but at the same time maintaining a safe reduction in the number of acute admissions.

\section{Protocol}

An SHO training programme was established. This had the specific aim of teaching SHOs how to assess and treat children with acute asthma and was combined with the continued facility to send children home at any time with a home treatment package of oral prednisolone, a suitable bronchodilator, and written information about treatment. The programme consisted of a one hour lecture in the first week that SHOs took up their posts and this was supplemented with written information. Doctors were accompanied when they saw their first asthmatic patients and were given advice and feedback on management decisions. Information folders were made available, containing peak flow charts, height and weight charts, and advice on the prescribing of age appropriate medication. Although guidelines were provided to aid identification of severe cases, there was no policy specifying which children should be admitted. A regular report was provided on the hospital's overall management of asthma.

After the first month of the study the treatment packages available to parents were extended to include peak flow meters and an open follow up appointment at a hospital dropin clinic run by an asthma nurse specialist. The assessment protocol was extended to children less than 18 months old. Prednisolone was not given routinely in this age group and bronchodilators were only supplied for home use if children showed a convincing response to treatment at referral. Those children unable to use the mouthpiece of a spacer were prescribed bronchodilators to be given either through a Volumatic (Allen and Hanburys) modified by the addition of a facemask, a 'split' Volumatic, or through a coffee cup. All medications were available for demonstration and dispensation 24 hours a day.

Parents of children seen in the initial months of the study were given symptom score diaries and asked to record daytime cough and wheeze, daytime activity, and medications received for a two week period after leaving the hospital. Symptoms were scored on a scale of 0 to 3 (absent, mild, moderate, and severe). This paper presents data from the first year of this programme.

\section{Results}

During the one year period, 20 SHOs were involved in the assessment of acute medical referrals. Of 687 children with acute asthma, $299(43.5 \%)$ were sent home. Sixteen reattended within one week and seven were subsequently admitted.

Readmissions within the study period accounted for $20 \%$ of the asthma admissions during the year. The number of referrals during the study were similar to numbers in previous years but there were fewer admissions (table 2).

Table 2 Outcome of patients seen in study 2 compared with previous years

\begin{tabular}{lllc}
\hline Year & No seen & Admitted & Sent home \\
\hline $1988-9$ & 677 & 606 & 71 \\
$1989-90$ & 592 & 527 & 65 \\
$1990-1$ & 630 & $\star$ & $\star$ \\
$1991-2$ & 687 & 388 & 299
\end{tabular}

*Study 1 took place during four months in $1990-1$ and so figures are not included. 


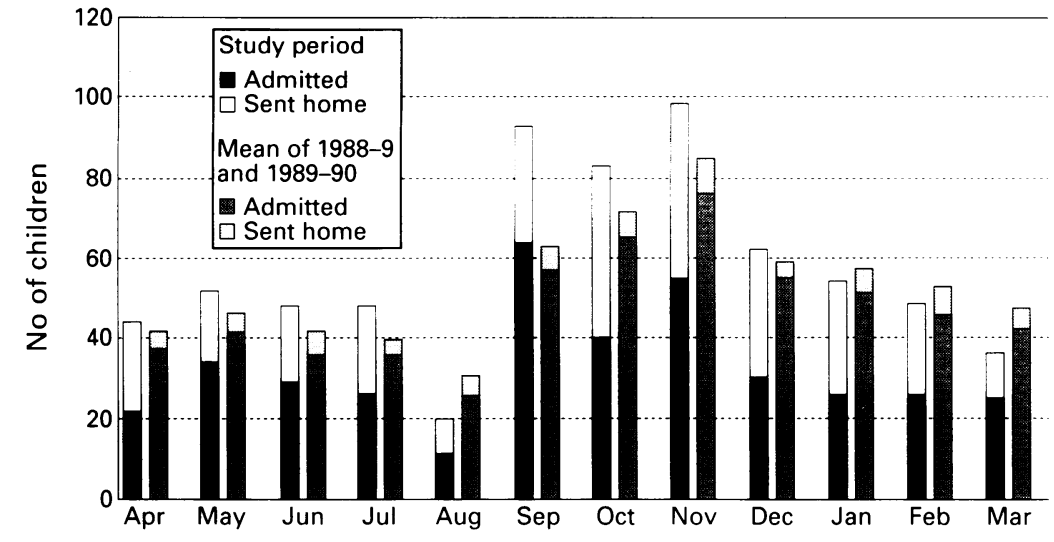

Figure 2 Study 2: outcome of monthly referrals compared with the mean values 1988-9 and 1989-90.

Table 3 Mean symptom score assessments

\begin{tabular}{|c|c|c|c|c|c|}
\hline & \multicolumn{2}{|c|}{$\begin{array}{l}\text { Duration of } \\
\text { symptoms (days) }\end{array}$} & \multicolumn{2}{|c|}{$\begin{array}{l}\text { Combined mean } \\
\text { first week scores }\end{array}$} & \multirow{2}{*}{$\begin{array}{l}\text { Regular } \\
\text { bronchodilator } \\
\text { (days) }\end{array}$} \\
\hline & Day & Night & Day $(0 \cdot 9)$ & Night $(0 \cdot 6)$ & \\
\hline Admitted [50/111 (45\%)] ${ }^{\star}$ & $7 \cdot 89$ & $7 \cdot 20$ & $2 \cdot 45$ & $1 \cdot 60$ & $6 \cdot 91$ \\
\hline Not admitted $[51 / 81(61 \%)]^{\star}$ & $7 \cdot 17$ & $5 \cdot 17$ & 1.97 & 1.71 & 3.35 \\
\hline
\end{tabular}

* Figures refer to the number of diaries returned in each group.

Figure 2 compares the proportions of children admitted and sent home in each month of the study with two prestudy years. Analysis by $\chi^{2}$ showed these differences in proportions to be significant at $p<0.01$ for all months except June and March, which were significant at $\mathrm{p}<0.025$.

Altogether $436(63 \%)$ children seen were self referrals. Of these, 203 (46\%) were sent home. Of the remaining 256 children referred by a GP, $96(37.5 \%)$ were sent home. Symptom score cards were given to 192 sets of parents. Just over $50 \%$ of these were returned. Scores from children sent home without admission were no worse than those from admitted children recorded from the day after they left hospital (table 3). Because of the low number of returns this data was not analysed statistically.

\section{Discussion}

These studies demonstrate how an increased number of asthma referrals to hospital can be safely managed at home. The studies were designed to set a standard of care and then ensure this standard was maintained. This has been achieved by developing an SHO training programme and by facilitating home treatment by parents. SHOs were deliberately not given a rigid protocol on which to base their management decisions. Previous researchers have advocated the use of asthma severity indices to determine the need for admission, ${ }^{78}$ but these have not always been shown to be helpful. ${ }^{9} 10$ This is because there are complex psychosocial factors specific to each family that determine the ability of the parents to cope at home with a sick child. These aspects of management cannot be comprehensively included within a scoring system and are best addressed using clinical acumen. Such clinical skills improve through teaching programmes and practical experience. When directed to doctors in the front line of acute medicine, this can lead to a more cost effective and rational use of medical facilities. The availability of treatment for use outside hospital enabled children to be sent home without undue delay. A telephone survey of 41 randomly selected UK hospitals suggested that this sort of facility was often poorly organised in many centres. Seven doctors on call stated that they did not use any such facility because it was their policy to admit all asthma referrals and in eight out of the remaining 34 hospitals, facilities were unavailable outside 'regular' working hours.

Only $5 \%$ of children sent home reattended during the same wheezy episode. This was substantially less than the $16 \%$ reattendance rate reported from a teaching hospital where the decision to admit was the responsibility of a registrar. ${ }^{11}$ This difference in reattendances probably reflects an increased use of home medication by children in our study.

Our studies suggest that a substantial part of the increase in admissions has been due to a shift in care from the community and into the hospital. Admission times are shorter but this may reflect a better use of effective treatment.

Despite fewer admissions, numbers remain higher than 20 years ago. This could be due to increased severity of referrals. Unfortunately, it is difficult to make accurate retrospective comparisons of asthma severity from casenotes, and studies that have attempted this have given inconsistent results. A hospital study in the South West Thames region failed to detect a change in the severity of admissions from $1975-85,,^{12}$ while another similar study in New Zealand reported increased severity. ${ }^{13}$

There is evidence for an increase in the prevalence of children with wheezing but this rise is small. ${ }^{14} 15$ The impact of this on asthma referral patterns may have been exaggerated by changing attitudes towards management and the increased use of 'asthma' as a diagnostic label. ${ }^{16} \mathrm{~A}$ much larger increase in the frequency of attacks has been reported, 141517 although not all studies confirm this. ${ }^{18}$ The factors underlying such changes must be environmental rather than genetic. Pollution, the exposure to cigarette smoke, and housing conditions favouring dust mite proliferation may all be important causes of bronchial hyper-reactivity, but there is little evidence that these factors have increased significantly over the last 20 years.

What has changed is the social environment of preschool children. This age group accounted for $68 \%$ of children referred in the second study and the previously documented increase in admissions was mainly due to the rising number of children under 5 years requiring inpatient treatment. ${ }^{5}$ During this period there has been increased provision of day care and play group facilities. The greater mixing of these children increases the mutual transmission of viruses. ${ }^{19}$ This probably increases the rate of respiratory infections leading to acute asthma exacerbations in those predisposed to wheezing. ${ }^{2021}$ 
The incidence of viral induced asthma attacks is also influenced by mixing in school age children. ${ }^{22}$ Asthma admissions peak when children return from school holidays and import new viruses that cause epidemics of wheezing in their asthmatic peers.

Although this hospital based study has been successful in reducing hospital admissions, strategies concentrating on asthma prevention are required. Improvement in primary care alone will not achieve this. ${ }^{23}$ Specific intervention programmes similar to those recently reported from America are needed. ${ }^{24} 25$ It would be appropriate to develop these forms from within the community, although asthma specialists should be involved in their design. This requires greater communication and integration between GPs and paediatricians with an interest in asthma. This is particularly important if a larger proportion of the primary care of asthma is to be delivered at home. Clear guidelines about asthma treatment have been published. ${ }^{26-28} \mathrm{~A}$ greater awareness of their recommendations is needed. This can be achieved by increased postgraduate education and the translation of concepts about treatment into practical achievements.

1 Hill A. Trends in paediatric medical admissions. BMf 1989; 298: $1479-83$.

2 Morgan M, Mays N, Holland WW. Can hospital use be a measure of need for health care? $\mathcal{f}$ Epidemiol Community Health 1987; 41: 269-74.

3 Crompton GK, Grant IWB, Bloomfield P. Edinburgh emergency asthma admissions service: report on 10 years experience. $B M 7$ 1979; ii: 1199-201.

4 Macdonald JB, Seaton A, Williams DA. Asthma deaths in Cardiff 1963-74: 90 deaths outside hospital. BMF 1976; i: $1493-5$.

5 Storr J, Barrell E, Lenney W. Rising asthma admissions and self-referral. Arch Dis Child 1988; 63: 774-9.

6 Godfrey S. Treatment of childhood asthma. In: Clark TJH, Godfrey S, Lee TH, eds. Asthma. London: Chapman and Hall Medical, 1992: 579-80.

7 Skoner DP, Fischer TJ, Gormley C, Martinez R, Bobbit RC, Holroyde J. Pediatric predictive index for hospitalisation in acute asthma. Ann Emerg Med 1987; 16: 25-31.
8 Fischl MA, Pitchenik A, Gardner B. An index predicting relapse and the need for hospitalisation in patients with acute bronchial asthma. $N$ Engl f Med 1981; 305: 783-9.

9 Rose CC, Murphy JG, Schwartz JS. Performance of an index predicting the response of patients with acute bronchial asthma to intensive emergency department treatment. N Engl F Med 1984; 310: 573-7.

10 Centor RM, Yarborough B, Wood JP. Inability to predict relapse in acute asthma. N Engl I Med 1984; 310: 577-80.

1 O'Halloran SM, Heaf DP. Accident and emergency department attendance by asthmatic children. Thorax 1989; 44: 700-5.

12 Anderson HR. Increase in hospital admissions for childhood asthma: trends in referral, severity, and readmissions from 1970 to 1985 in a health region in the United Kingdom. Thorax 1989; 44: 614-9.

13 Dawson KP. The severity of asthma in children admitted to hospital: a 20 year review. $N Z M e d f$ 1987; 100: 520-1.

14 Burney PGJ, Chinn S, Rona RJ. Has the prevalence of asthma increased? Evidence from the national study of health and growth 1973-1986. BMF 1990; 300: 1306-10.

15 Burr ML, Butland BK, King S, Vaughan-Williams E. Changes in asthma prevalence: two surveys 15 years apart. Arch Dis Child 1989; 64: 1452-6.

16 Hill R, Williams J, Tattersfield A, Britton J. Change in use of asthma as a diagnostic label for wheezing illness in of asthma as a diagnostic label for
schoolchildren. BMF 1989; 299: 898 .

17 Fleming DM, Crombie DL. Prevalence of asthma and hay fever in England and Wales. BMF 1987; 294: 279-83.

18 Strachan DP, Anderson HR. Trends in hospital admission rates for asthma in children. $B M \mathcal{F} 1992 ; 304: 819-20$.

19 Collet JP, Ducruet T, Floret D, Cogan-Collett J, Honneger $D$, Boissel JP. Day care attendance and risk of first infectious disease. Eur $\mathcal{F}$ Pediatr 1991; 150: 214-6.

20 Horn MEC, Reed SE, Taylor P. Role of viruses and bacteria in acute wheezy bronchitis in childhood: a study of in acute wheezy bronchitis in childhood:

21 Carlsen KH, Ostravik I, Leegard J, Hoeg H. Respiratory virus infections and aeroallergens in acute bronchial asthma. Arch Dis Child 1984; 59: 310-5.

22 Storr J, Lenney W. School holidays and admissions with asthma. Arch Dis Child 1989; 64: 103-7.

23 Hutchison TP, Durojaiye L, Madeley RJ. Improved primary care does not prevent the admission of children to hospital. Arch Dis Child 1987; 62: 649-50.

24 Hughes DM, McLeod M, Garner B, Goldbloom RM. Controlled trial of a home and ambulatory program for asthmatic children. Pediatrics 1991; 87: 54-61.

25 Clark NM, Feldman CH, Evans D, Levison MJ, Wasilewski Y, Mellins RB. The impact of health education on frequency and cost of health care use by low income frequency and cost of health care use by low income
children with asthma. $\mathcal{f}$ Allergy Clin Immunol 1986; 78: children

26 Warner JO, Goltz M, Landau LI, et al. Management of asthma: consensus statement. Arch Dis Child 1989; 64: 1065-79.

27 Warner JO. Asthma: a follow up statement from an international paediatric asthma consensus group. Arch Dis Child 1992; 67: 240-8.

28 Woodhead $M$, ed. Guidelines on the management of asthma. Thorax 1993; 48 suppl No 2 . 